\title{
Shades of Chaos: Lessons Learned About Lessons Learned About Forecasting El Niño and Its Impacts
}

\author{
Michael H. Glantz
}

Published online: 7 March 2015

(C) The Author(s) 2015. This article is published with open access at Springerlink.com

\begin{abstract}
The troubled forecast of El Niño's onset in 2014 requires an explanation as well as an open dialogue with the user community that depends on such an important forecast. A review of the forecasts on the Internet reflects two different perceptions about what transpired. The forecast community suggests they got it right, while the popular media suggests forecasters got it wrong. Why such a gap? The major El Niño that was alluded to by several organizations did not materialize when or even as expected. A science-fed media frenzy took place about an event considered in retrospect to have been an unusual borderline (weak) El Niño event, "trickiest ever to forecast." That is understandable, as the science of El Niño is still on a learning curve. But it suggests that the forecasting of $\mathrm{El}$ Niño's onset is still in an experimental phase and not yet operational. Forecasting its onset (as a specific event) should be separated from forecasting its behavior and impacts (as a process) once the onset has been assured. Whenever a forecast is made, someone is responding to it. Therefore, such a distinction is necessary for the benefit of those societies and economic sectors affected by El Niño.
\end{abstract}

Keywords 2014 El Niño forecast .

El Niño $\cdot$ ENSO $\cdot$ Experimental

forecast · Oscillations · Teleconnections

This article is dedicated to the memory of Beijing University Professor Wang Shao-wu, an El Niño scholar and a dear friend.

M. H. Glantz $(\bowtie)$

Consortium for Capacity Building (CCB), Institute of Arctic and Alpine Research (INSTAAR), University of Colorado, Boulder, CO 80301, USA

e-mail: mickeyglantz@hotmail.com

\section{Introduction}

Whenever a forecast of the possible onset of an El Niño event has been released to the media by a group in the scientific community, societies' proverbial ears and eyes open wide. That is the way it has been since the appearance in 1982-1983 of the first "El Niño of the Century." That event also could be called the "El Niño of the Governments," because that is when governments like Australia and the United States finally took serious notice of El Niño and its potentially adverse impacts on their economies.

El Niño results from anomalous air-sea interactions that occur irregularly in the tropical Pacific Ocean. It recurs at roughly 2-10 year intervals and its intensity can range from weak to extraordinary. The anomaly results from a weakening in the intensity of westward-flowing winds along the equator. This weakening of surface winds enables the warm water that has piled up in the Western Pacific to shift eastward toward the central and eastern Pacific. Rainproducing cloud systems follow the shifting warm water and cause normally wet regions to become drier (for example, Southeast Asia, the Philippines, and Australia) and the eastern normally arid and hyperarid regions along the western coast of South America to become wetter (for example, Peru, Ecuador, and Northern Chile) (Fig. 1).

Until the late 1950s, El Niño was viewed as a local/ western South America regional problem with consequences limited to Peru, Ecuador, and Northern Chile. It was a local, anomalous air-sea interaction with known consequences for local anchoveta fishermen (Fig. 2), farmers, and herders. That view changed abruptly, however, in the early 1970s when a major El Niño event occurred with notable impacts on commodity prices around the globe and on the Peruvian economy. The impact fell especially on Peru's fishmeal industry, when El Niño-as- 


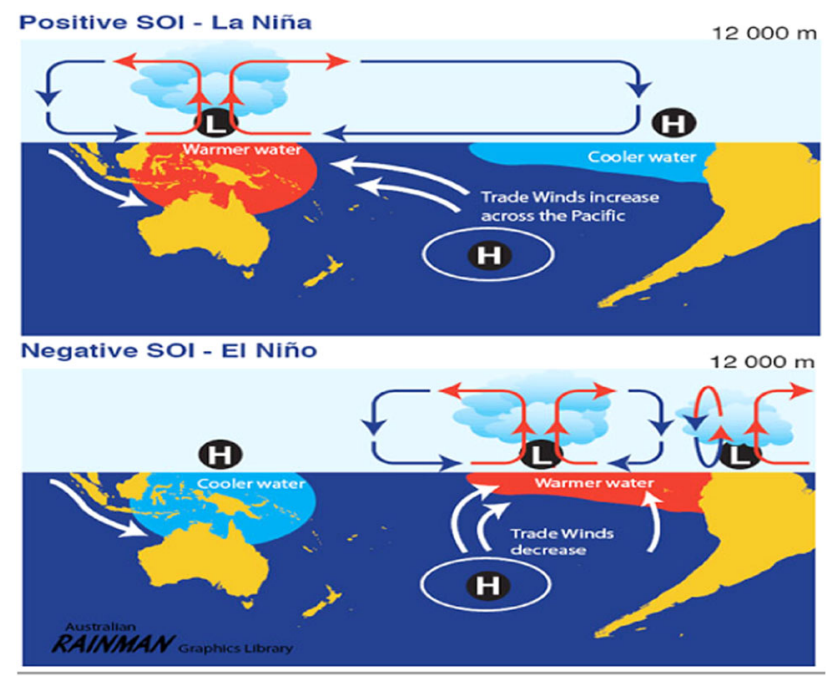

Fig. 1 El Niño-Southern Oscillation. Source Queensland Government, Australia (n.d.)

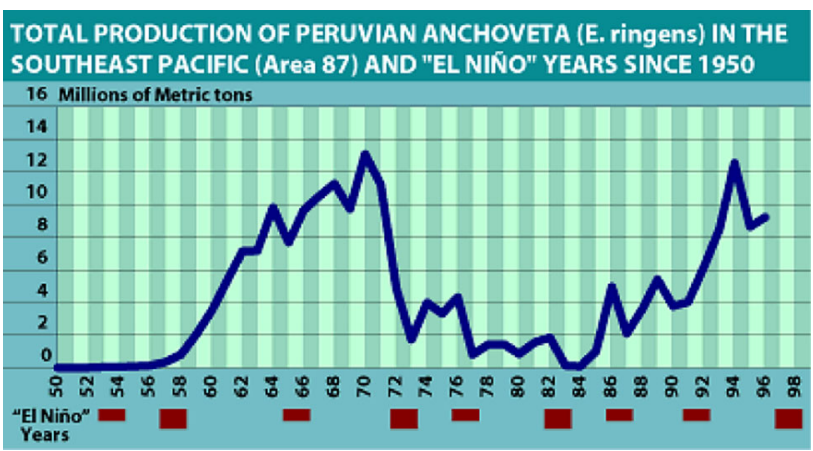

Fig. 2 Total production of Peruvian anchoveta in the Southeast Pacific and "El Niño" years since 1950. Source FAO (n.d.)

predator combined with the impacts of overfishing to cause the sudden collapse of the fishery, which was a major source of foreign currency for the Peruvian government.

The 1972-1973 El Niño proved to be the "El Niño of the Scientists," as scientific research interest in the phenomenon was stimulated by the recognition of global influence of this anomalous regional air-sea interaction. El Niño was no longer viewed as a local phenomenon, but rather was seen as a Pacific, basin-wide phenomenon with global climate, water, weather, and socioeconomic consequences (Bjerknes 1966, 1969). El Niño episodes were linked, through natural processes and through statistical analyses, to changes witnessed in many distant parts of the globe. Those changes are "teleconnections," or consequences, at some distance from the stimulus in the tropical Pacific, for example, an El Niño episode. During an El Niño period, weather patterns around the globe are also affected to varying degrees, most often in adverse ways. Such teleconnections, as with the El Niño phenomenon itself, are influenced by other local to global so-called oscillations in the atmosphere and oceans. Figure 3 is a generic map of expected teleconnections.

Teleconnections are a key interest in the scientific and forecast communities' drive to produce reliable forecasts of El Niño's onset months if not a few seasons in advance of an expected event. Successful forecasts of its onset have been elusive. To put it bluntly, overall success has been virtually non-existent. The good news, however, is that once an El Niño episode has locked in (for example, the onset has become undeniable), there is considerable value in forecasting - or at least preparing for-several of its known impacts on climate and society, particularly as it reverberates globally through its teleconnections.

The 1982-1983 "El Niño of the Century" was unexpectedly followed 14 years later by the devastating 1997-1998 El Niño, also labeled as the "El Niño of the Century!" It was simultaneously the "El Niño of the People," because people on the streets in countries worldwide began to take notice of El Niño as a result of electronic and printed local media coverage and weather warnings. Popular references to the phenomenon became evident: "El Niño made me do it" or "Blame El Niño," for example, and commercial advertisements selling products also touted their products as necessities to help people prepare for the local consequences of the expected El Niño event.

Today, civil societies as well as their governments and numerous socioeconomic sectors of society become concerned when the onset of an El Niño is forecast as likely to occur with some degree of probability provided by forecasters. Although people on the street may not know exactly what an El Niño is or what specifically it might do, they do know that an El Niño is often associated with bad news. Clearly, the mention of "El Niño now captures attention of the media and, therefore, the public especially when the media highlight El Niño articles with eyecatching sensational headlines as in Fig. 4.

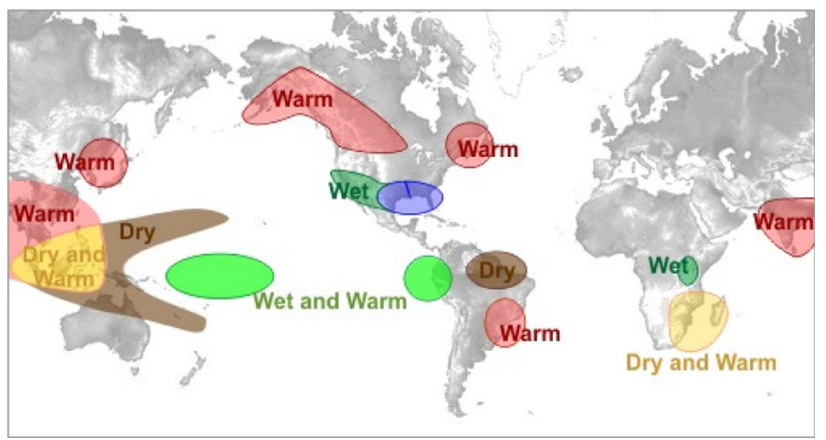

Fig. 3 El Niño effect during December through February. Source National Weather Service, U.S.A. (n.d.) 
Fig. 4 Weblines of popular news articles taken from the Internet. Source The author

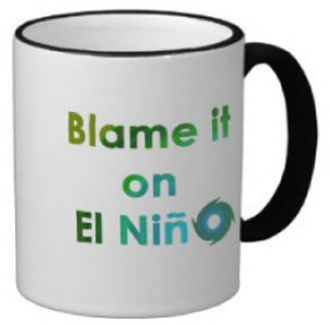

\section{Forecasting El Niño}

Various large-scale computer-modeling activities (as of today there are 17 dynamical models and nine statistical models) have been focused during the past two decades on monitoring as well as forecasting the El Niño-Southern Oscillation (ENSO) quasi-periodic cycle that encompasses three phases: El Niño, La Niña, and El Niño Neutral (the period between the ENSO extremes). The International Research Institute for Climate and Society of the Earth Institute, Columbia University monitors the predictions monthly of 19 modeling activities and records them in an ensemble (plume) chart format as shown in Fig. 5. The figure also shows the dynamical and statistical models used in the plume.

We know that El Niño science is about improving the understanding of atmospheric and oceanic processes in order to reduce uncertainties about the phenomenon. In spite of the modeling efforts and observations of El Niño's characteristics from space and in the ocean, the track record of success in forecasting the onset of an El Niño event remains unclear, and is dependent on the variables used to determine a successful forecast from an unsuccessful one. Officials argue that their forecasts were good, including the ones about the 2014 El Niño forecasts (L'Heureux 2015). The official count of successes I believe can be challenged. With regard to El Niño, scientists since 1982-1983 have been forecasting its onset. When an event does not occur that they had forecast, they say: "We know what we missed and now we understand it," only to misforecast the onset of the next warm event.

For example, for the 1997-1998 El Niño, none of the models (dynamical or statistical) clearly captured and forecast the onset of that extraordinary event even as late as December 1996. Yet its onset emerged a few months later

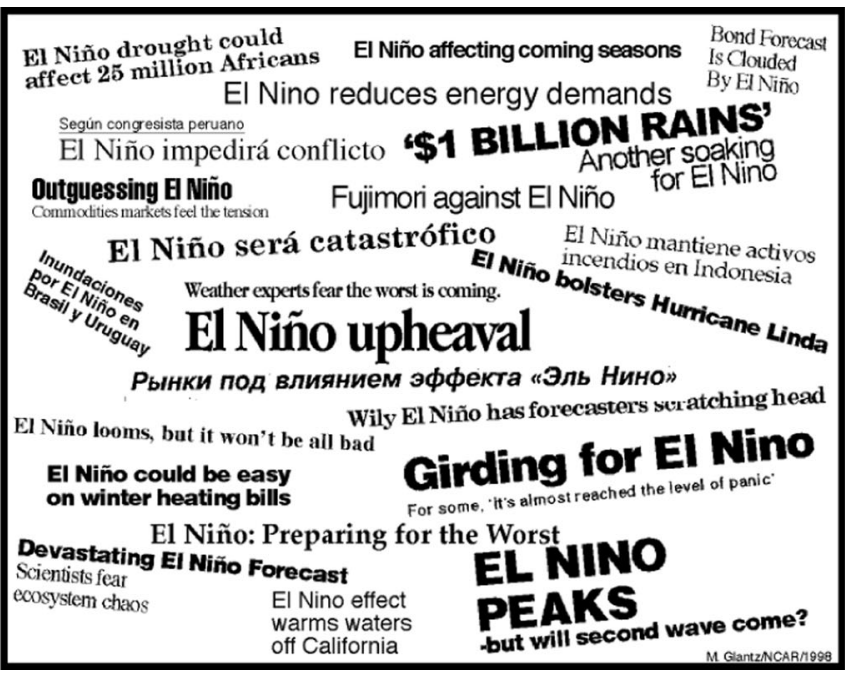

in the equatorial Pacific. After the event's onset had locked in, some organizations began to rewrite their forecast history in a way favorable to their organization (personal communication in 1999). For example, at least one forecast institution after-the-fact, demanded its forecasters to report in print that its model had correctly forecast the major El Niño event as early as December 1996. ${ }^{1}$ This casts doubt on official statements about success rates for forecasting the onset of El Niño events (NB: Please read the two articles published in the same journal 8 months apart in 1999).

\section{Forecasting El Niño in 2014}

We are now half way through the second decade of the twenty-first century, with numerous recent forecasts in the late winter and early spring of 2014 of a potentially major El Niño. Oceanic conditions early in the year sparked the attention of ENSO researchers, who had felt that it was time for a major El Niño to take place, following a relatively quiet period. In early 2014, forecasts of a possible major El Niño event were reported in the media based on information supplied by forecasters. The race was on: which forecaster, group, or center would get this forecast right, and be the first to do so. Several El Niño watchers stated: "we are due for a major El Niño."

Such comments made early on were soon followed by comparisons of the atmospheric and oceanic conditions occurring in Spring 2014 to those that preceded the 1997-1998 "blockbuster" El Niño event. Perhaps the best example of this comparison came from NASA (NASA

\footnotetext{
${ }^{1}$ As an example, compare Barnston, He, and Glantz (1999, February) with Barnston et al. (1999, September).
} 
Fig. 5 An example of the monthly plumes of Model ENSO predictions. Source International Research Institute, Columbia University and NOAA Climate Prediction Center (2014)

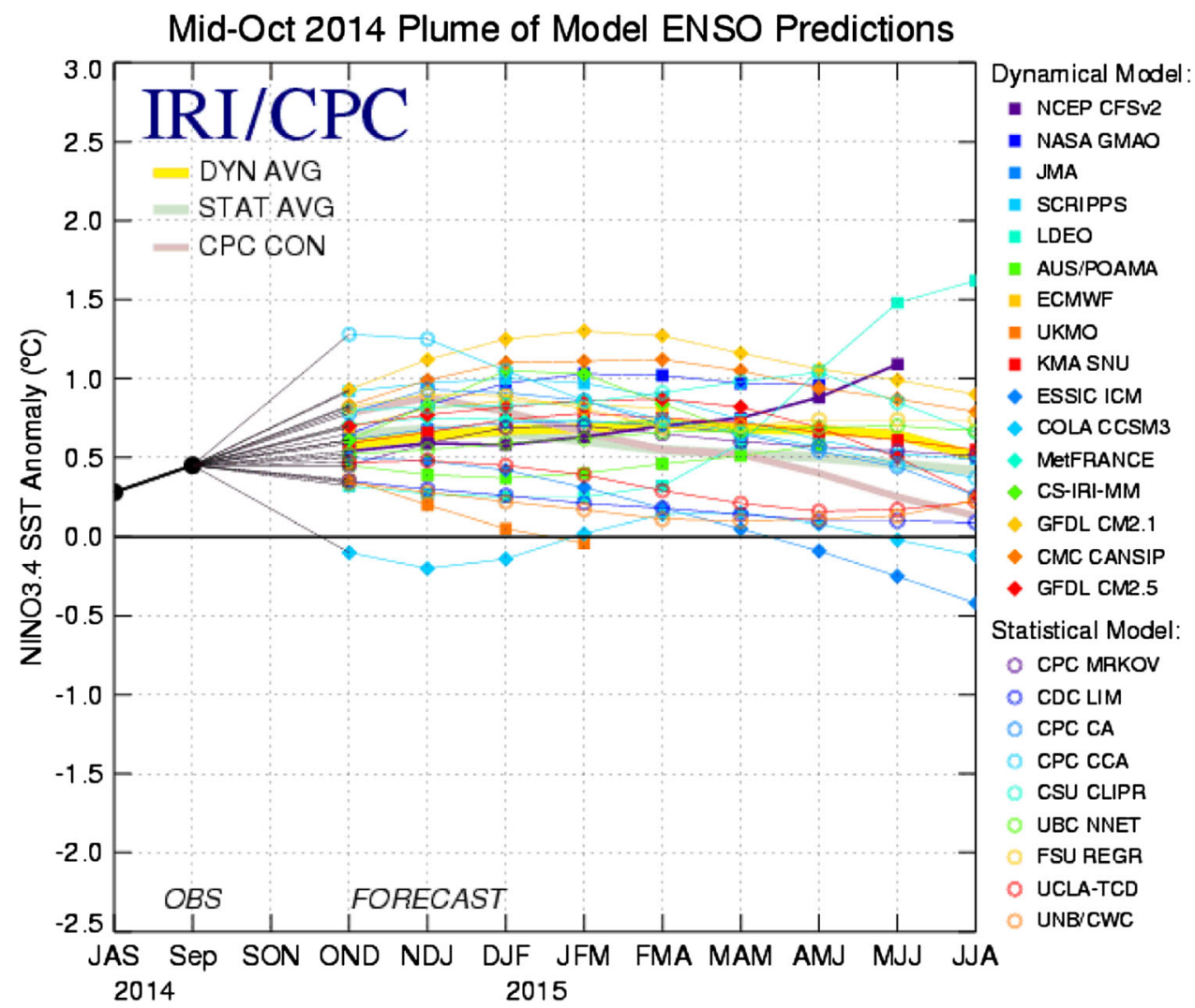

Science News 2014) in an article entitled "El Niño: Is 2014 the new 1997?" The article does not make a forecast but the comparison made therein of existing sea surface conditions in the tropical Pacific raised interest and anticipation by readers of a possible super El Niño: "A pattern of sea surface heights and temperatures has informed me of the way the Pacific looked in the spring 1997," says Bill Patzert, a climatologist at NASA's Jet Propulsion Laboratory. "That turned out to be the precursor of a big El Niño."

Forecasters (some of them) were saying that the El Niño of 2014-2015 was shaping up to be like or worse than the 1997-1998 episode. The probability for that worst-case scenario-a major El Niño event-was stated as high as 80-90\%. The following table provides but one perspective on linking quantitative probability statements with qualitative terms. It is shown here as illustrative and not definitive of how probability statements might be interpreted by the general public receiving a probabilistic forecast (Table 1).

As an example of the impact of an El Niño forecast, The $H i n d u$, a South Asian newspaper responded to the forecasts with an article entitled "Strongest in 15 Years, 2014 El Niño Could Hit India Hard." The 12 June article noted that there was "a 90 percent chance of striking this year, according to the latest forecast released to The Guardian." (The Hindu 2014). The article then centered on the
European Centre for Medium-Range Weather Forecasts (ECMWF), quoting staff who noted: "It is very much oddson for an event, [...] $90 \%$ of their scenarios deliver an El Niño. 'The amount of warm water in the Pacific is now significant, perhaps the biggest since the 1997-1998 event." (The Hindu 2014). The ECMWF scientist interviewed did say that the next month or two would clarify the situation about event's magnitude.

A caveat is necessary about the intensity level of a possible mid-2014 El Niño. Many forecasters did not directly address the intensity aspect of the mid-2014 El Niño event that they were forecasting. Based on comparisons from the scientific community, media articles reporting on the possibility of an El Niño event did use that scientific input to compare some key El Niño-related characteristics and behavior of the atmosphere and the ocean in the tropical Pacific to those that existed in the buildup to the 1997-1998 "El Niño of the Century." Although such comparisons did not per se constitute a forecast of what was likely to occur, they did accompany the forecast thereby planting the idea in the minds of the readers that a major El Niño event could be on the way for 2014-2015.

\subsection{Forecasts Before Mid-June 2014}

By early summer, some research groups began to express doubts about the reality of a 2014 El Niño. In mid-May 
Table 1 Some specific words to convey specific levels of certainty

\begin{tabular}{lll}
\hline $100 \%$ & Give or take about $6 \%$ & Certain \\
$93 \%$ & Give or take about $12 \%$ & Probable \\
$75 \%$ & Give or take about $10 \%$ & Chances about even \\
$50 \%$ & Give or take about $10 \%$ & Probably not \\
$30 \%$ & Give or take about $5 \%$ & Almost certainly not \\
$7 \%$ & & Impossible \\
$0 \%$ & & \\
\hline
\end{tabular}

Source Hall (2011)

2014, a science blog reported the following in an article entitled "Super Strong El Niño in 2014?" noting:

Conditions in the Pacific Ocean continue to suggest that a super strong El Niño might be forming in 2014 [...] Some similarities exist between the ocean and atmospheric state right now compared to observations shortly before the onset on the 1997-1998 El Niño event, one of the most potent El Niño events of the 20th century [...] While El Niño in 2014 cannot be guaranteed [according to Australia's Bureau of Meteorology], the likelihood of an event developing remains at least at $70 \%$ and they are at El Niño ALERT level. (The Watchers 2014).

The following figure (Fig. 6) presents a small set of weblines from news sources. They indicate that a major El Niño was expected to occur, according to El Niño modeling output and observations of tropical Pacific Ocean temperatures. They represent a mix of science pronouncements and media as well as scientific hype. For example, though reported on the Internet by media, it was a NASA news publication that headlined its article with "El Niño: Is 2014 the new 1997?" (NASA Science News 2014).

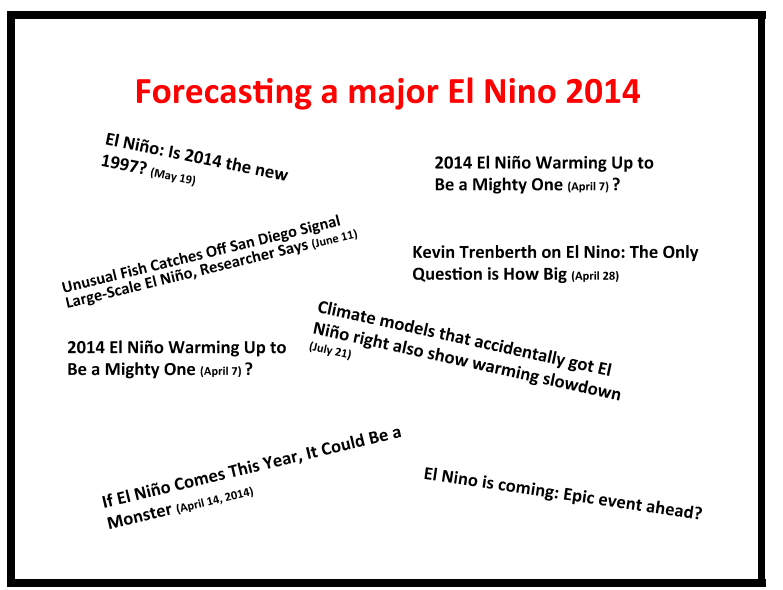

Fig. 6 Weblines from news sources that appeared on the Internet before mid-June 2014. Source The author (December 2014)

\subsection{Forecasting After Mid-June 2014}

In mid-June, an article in The Hindu reported that "forecasters at the US government's Climate Prediction Center said on June 5 that time was running out for a significant El Niño to be set in train." By early summer, forecasts of the onset of a major El Niño had all but disappeared from news headlines. For the first time, an early forecast of the onset of an El Niño with a high probability of being correct was later "downgraded" by major forecast centers, for example, NOAA Climate Prediction Center (CPC), International Research Institute for Climate and Society (IRI), Bureau of Meteorology (BOM) of Australia, among others. These centers, however, also noted that if an event were to occur in late 2014, it was expected now to be a "weak" event. This was a far cry from what El Niño forecasters had been saying to the media six months earlier. In late July on a climate skeptic's website, the writer poked fun at the forecast with a blog entitled "El Niño is Dead and Gone."2

An early August article on El Niño (Miller 2014) was entitled "El Niño Fizzle: No Relief Likely for California Drought." It started with "All that you've been hearing about El Niño coming to wash California out of its threeyear drought: fahgettaboudit. Federal scientists now say the odds of those peculiar ocean conditions often associated with wet winters here have diminished substantially, and there now is a $65 \%$ chance of El Niño by late Fall-early Winter, right when we'd be hoping for rain and snow to return. As recently as a month ago, modelers at NOAA's Climate Prediction Center had those odds pegged closer to 80 percent."

The article continued: "More important is the anticipated strength of the pattern, which NOAA forecasters now characterize as "weak'." It also quoted Bill Patzert of NASA's Jet Propulsion Laboratory (JPL), an El Niño researcher, who commented about the 2014-2015 El Niño forecast_- "It's a flop" (see Fig. 7).

\section{El Niño Forecasts and the Public}

To be sure a forecast is just a forecast and it does not come with a guarantee that it will be completely accurate. It also does not come with a warranty that compensates for the costs incurred in responding to the onset forecast of an $\mathrm{El}$ Niño that eventually does not occur. But the public is not well versed in probabilities associated with hydro-meteorological events. They rely on the forecast community to provide reliable and credible estimates of potential hazards, including those related to an El Niño.

\footnotetext{
$\overline{2}$ https://emsnews.wordpress.com/2014/07/25/el-nino-is-dead-andgone/.
} 
Fig. 7 Weblines of news articles taken from the Internet. Compiled by the author (December 2014) (NB: A search on the Internet for the articles noted above reveal the various forecast centers that downgraded the probability of an El Niño in 2014)

\section{Backtracking on the El Nino 2014 Forecast}

- Bad News For California: NOAA Lowers Chance Of El Niño To 65\%, Predicts A Weak One (August 7)

- El Nino 2014 on hold? Odds of development take a hit (August 9)

- El Nino Seen Delayed to End of Year as Australia Stays on Watch (August 26)

- National Weather Service backtracking some on El Nino forecast (August 7)

- Drought-busting El Niño looking less likely (August 8)

- Dry Western U.S. May Not Get Help From El Niño, Forecasters Say (August 8)

- El Niño Fizzle: No Relief Likely for California Drought (August 8)

- Odds Against Formation of a 'Super El Nino,' Experts Say (June 17)

- Scientists were expecting a big El Niño this year. So where did it go? (August 13)
What the public generally knows about the El Niño phenomenon comes from scientists by way of the media as purveyors if not translators of El Niño science. The public may not find it easy to distinguish between scientific statements and scientific hype. The media are not educators of the public; that is not their main responsibility. They are businesses and one way to increase visibility (and readership) is to startle the public with eye-catching headlines that may exaggerate the issue but captures the reader's attention. Stories involving interviews with scientists that are proven to be hype, indirectly as well as directly, erode the trust of civil society and its leaders in the integrity of the scientific community and the credibility of its forecasts. For its part, the public must have confidence in climaterelated forecasters for it to take their forecasts seriously.

However, in the present circumstance even if the public was savvy enough to discount the hype about the El Niño that appeared in the popular press, they would have fared only slightly better. Researchers at NOAA have examined the guidance distributed by the NOAA Climate Prediction Center (CPC) in regard to the currently nonexistent El Niño event. While CPC had been much more conservative in its statements regarding the magnitude of the warming, they were too confident in the probability of an El Niño occurrence. Since late August 2014, the CPC had in its monthly updates consistently forecast (with $\sim 60 \%$ probability) that El Niño would emerge within the next two months of the issuance of the forecast. This was partly due to the consistent errors of the models predicting the future state of sea surface temperatures in the tropical Pacific.

\section{Other Oscillations in the Climate System}

Why is the onset of an El Niño so hard to predict with a reasonable degree of reliability, given all that has been learned about climate over the past 30 years? A significant part of the reason is that the climate system is chaotic. The chaotic aspect of climate describes the inherent unpredictability present in the behavior of complex natural systems (Merriam-Webster n.d.). Climate scientists understand this characteristic of the systems they study. But in the models they create there is a tendency to hold constant some of Earth's oscillations that can influence the ENSO cycle, thereby focusing mainly on the air-sea interactions in the tropical Pacific. In the social sciences this would be considered an example of selective inattention.

When climate scientists say something behaves chaotically, they do not necessarily mean that it behaves without rhyme or reason. What they really mean to convey is that the behavior of the climate system is very sensitive and it can react disproportionately to just about any little disturbance. This implies that not only are weather systems and ENSO chaotic phenomena, but also that the whole system or network of climate variations is very sensitive. That the entire system is chaotic has a profound effect on the scientist's ability to forecast El Niño's onset accurately or to predict its impacts on societies and ecosystems worldwide.

There are several climate "oscillations" on monthly to decadal time scales that influence each other and impinge on the forecaster's ability to provide a reliable if not perfect 
prediction of the onset and strength of individual ENSO events or their teleconnected socioeconomic and ecological impacts. Hence, degrees or shades of chaos are introduced into forecasts of the ENSO process. In the Pacific basin, the Madden-Julian Oscillation (MJO) varies with a time scale of 30-60 days (Hendon and Salby 1994). It can trigger El Niño events and/or can interfere with the teleconnections that bring El Niño impacts to North America and other locations around the globe.

On longer time scales, the Pacific Decadal Oscillation (PDO) and the Indian Ocean Dipole (IOD) act on interannual to decadal time scales and affect the strength and structure of ENSO events as well as the location and intensity of their teleconnected impacts. Similarly, the Arctic Oscillation (AO), the North Atlantic Oscillation (NAO), and the Atlantic Multidecadal Oscillation (AMO) each acts in its own way as intervening climate variations in the North Atlantic and European sectors. They each tend to disrupt the climate system enough to make accurate prediction a challenge not only in terms of the impacts of ENSO but also of the onset of either an ENSO warm or cold extreme itself.

When the onset of an El Niño or a La Niña event is forecast to occur, the climate modelers making the prediction have assumed the persistence of the current (existing) conditional varying states (phases) of the various known climatic "oscillations." The significance of their sensitivity to the ENSO prediction is an area of incomplete, but growing, understanding in the science of climate prediction.

\section{El Niño and the El Niño Forecast Community}

El Niño forecasters and researchers appear to have been somewhat surprised by the absence over the past decade of El Niño events of major significance. Climate Central (6 November 2014) in a story about the 2014 El Niño forecast entitled "Waiting for El Niño. Still. Again" reported "The most notable example was the expected El Niño in 2012 that rapidly fizzled out. 'It can't keep not happening,' Halpert said, because otherwise they're over-forecasting. And two fizzles in a row makes future forecasting decisions tougher" (Thompson 2014). There has been no attentiongrabbing, blockbuster event (media headlines notwithstanding) since 1997-1998, as measured in terms of major losses of life and property. Researchers and forecasters have been waiting for the onset of a major El Niño episode, which might help them to shed more research light on the phenomenon and to improve their ability to make better predictions of its onset in the future. Of course, a missed forecast could provide the same opportunity to improve understanding of El Niño behavior.
It is time for the El Niño research and forecast communities to come to terms with the fact that El Niño-as a recurring anomalous result of air-sea interactions in the tropical Pacific Ocean-is just another climate-related expression of variability on an intradecadal (or interannual) time scale. Perhaps one reason that the ENSO phenomenon stands out in the minds of the public, aside from its potential adverse impacts worldwide, is that it has been given a popular, memorable name: El Niño. El Niño refers to the Christ Child as the phenomenon was so named by Peruvian geographers as early as 1891 because ocean currents off the western coast of South America would weaken or shift around Christmas time, lasting for a few months: a seasonal change. But every so often in a 2-10 year time frame the strong westward flowing current would not return. The cold, upwelled nutrient rich waters off the Peruvian coast would be weakened as warm water invaded the coastal area. Fish populations declined drastically and guano birds that thrive on the abundant fish would starve to death and wash up on shore by the hundreds of thousands to millions.

Over the last five decades scientists have identified other so-called oscillations in the climate system, each with its scientific name:

- North Atlantic Oscillation (NAO)

- Arctic Ocean circulation regime

- Atlantic Multidecadal Oscillation (AMO)

- Tropical Atlantic decadal variability (the Atlantic dipole)

- Madden-Julian Oscillation (MJO)

- Pacific Decadal Oscillation (PDO)

- Indo-Pacific Warm Pool (IPWP)

- Also called Warm Pool Oscillation (WPO)

- Antarctic dipole

- South Atlantic Sub-tropical Dipole (SASD)

- Indian Ocean Sub-tropical Dipole (IOSD)

In his PowerPoint presentation "Decadal climate variability: Societal impacts, phenomena, problems and prospects," Mehta (2004) identified several decadal and multidecadal scale climate variabilities on what he called civilization time-scales. He noted "Success in understanding and prediction of short-term climate variability and long-term climate change, especially at sub continental to state/province scale, depends crucially on success in understanding and prediction of decadal-multidecadal climate variability." He concluded by suggesting that researchers "must not limit our search for causes of decadal climate variability to internal processes only $[\ldots]$ Decadal climate predictability is a function of external forcings and internal variability."

This is not to say that the patterns of variability and teleconnections that are linked to these oscillations are not 
represented in coupled climate forecast models; all the structures are there at the beginning of each forecast. The difficulty is that the patterns evolve and change over a long time scale from months to decades, but not as quickly as the weather, which changes in days. Forecast models predict these changes, but, because the changes are slowly evolving, the change is very small compared with the fast weather changes that are also predicted in the forecast model. Because they are both small and highly sensitive (chaotic), the changes in all the modes and oscillations are easy to get wrong. That is another reason why El Niño has been the center of attention; ENSO is the largest in amplitude of all the climate oscillations, except for the annual cycle. El Niño does not reappear on any specific time scale, except that it can reasonably be anticipated at least once in a decade in an event of unknown intensity. In other words, it is time to stop treating El Niño as a special variability and to put it back in the variability box along with interannual, and decadal scale variability.

El Niño is especially interesting as a climate-related phenomenon because of its physical or statistical linkages (that is, teleconnections) worldwide. There is a heightened degree of reliable expectation of foreseeable anomalies such as droughts, floods, fires, or disease outbreaks. While the forecast of El Niño's onset might still be elusive, once an event has been determined to have begun, a reliable cascade of forecasts of downstream impacts can be identified, many of which can be prepared for. This suggests that until the forecasts of El Niño's onset become more reliable, those wishing to act on the basis of the reliability of an El Niño forecast should limit their response to actions that would be taken after an El Niño has locked-in.

Teleconnections associated with an El Niño have been identified as a result of known physical (atmospheric and oceanic) processes, as a result of statistical analyses, or as a result of belief or wishful thinking (not supported as yet scientifically). Some teleconnections can be considered to be fairly strong, that is, reliable, enabling those linked societies to take action, once the onset of an event has been confirmed. Other teleconnections may only occur with lower degrees of expectations, because the magnitude of the El Niño event can vary from minor to major. It is likely as well that the life cycle of El Niño is influenced by the varying phases of other oscillations while the El Niño event is running its course.

\section{Concluding Thoughts}

Two decades ago I wrote an article entitled "Forecasting El Niño: Science's Gift to the 21st Century" (Glantz 1994). In a sense I was right: scientists made us aware of the phenomenon and raised not only our awareness of what it was, but also what it could do in terms of socioeconomic impacts to various societies around the world. But what I got wrong was my belief that the researchers had already unlocked, or at least were on the verge of unlocking, the mystery of the precursors to an El Niño's onset, an invaluable prediction. As it has happened, most forecasts of El Niño's onset have been incorrect. What is valuable, however, is the realization that once an El Niño locks in it will likely run its course for the following year or so. El Niño conditions can be expected to do so because of physical processes in the ocean-atmosphere interplay.

I had high hopes and expectations that El Niño's deepest mysteries would become known before the end of the twentieth century. I was wrong. There have been too many missed forecasts with regard to an El Niño's onset. As far as the general public (civil society) is concerned, the media reports accurately on what the scientists tell them about an impending El Niño event. The tendency is to believe the forecasters. However, when no El Niño appears or if the event turns out to be less intense than suggested by researchers and/or the media, the public becomes skeptical about the reliability of El Niño forecasts (Fig. 8).

I now believe there is a need to separate the stages of the El Niño process that we wish to forecast. To that end we can separate (1) the onset forecast from (2) the post-lock-in forecast. The onset forecast should be considered as still experimental as all of the pieces to the El Niño puzzle have not yet been effectively put together. The post-lock-in phase forecast would be considered an operational forecast. Making this distinction would shift the focus to forecasting the El Niño intensity (distinguishing between weak, moderate, strong, extraordinary), duration, and ending as well as the likely teleconnections (societal and ecological impacts) associated with the different levels of intensities. For both onset and lock-in phases, the state of the various socalled oscillations needs to be considered.

Without the separation of two distinctly different levels of forecast certainty, civil societies inevitably blame the scientific community for unwittingly misleading them astray. This limited predictive capacity prompts societies to prepare for the impacts of an El Niño that may not occur. Actions based on forecasts have real, often costly, consequences for those who trust in science. After a while that trust will erode.

The forecast of El Niño's onset in 2014 demands an explanation and a conversation with end users about why this forecast seemingly failed. The major, if not blockbuster, El Niño that was expected by several scientific organizations did not materialize when or as expected. That is understandable, given the complexities associated with the numerous oscillations in the global atmosphere and the 
Fig. 8 The El Niño cartoon. Source Glantz (2001, p. 266). Image by Rob Pudim, cartoonist. Text by Glantz

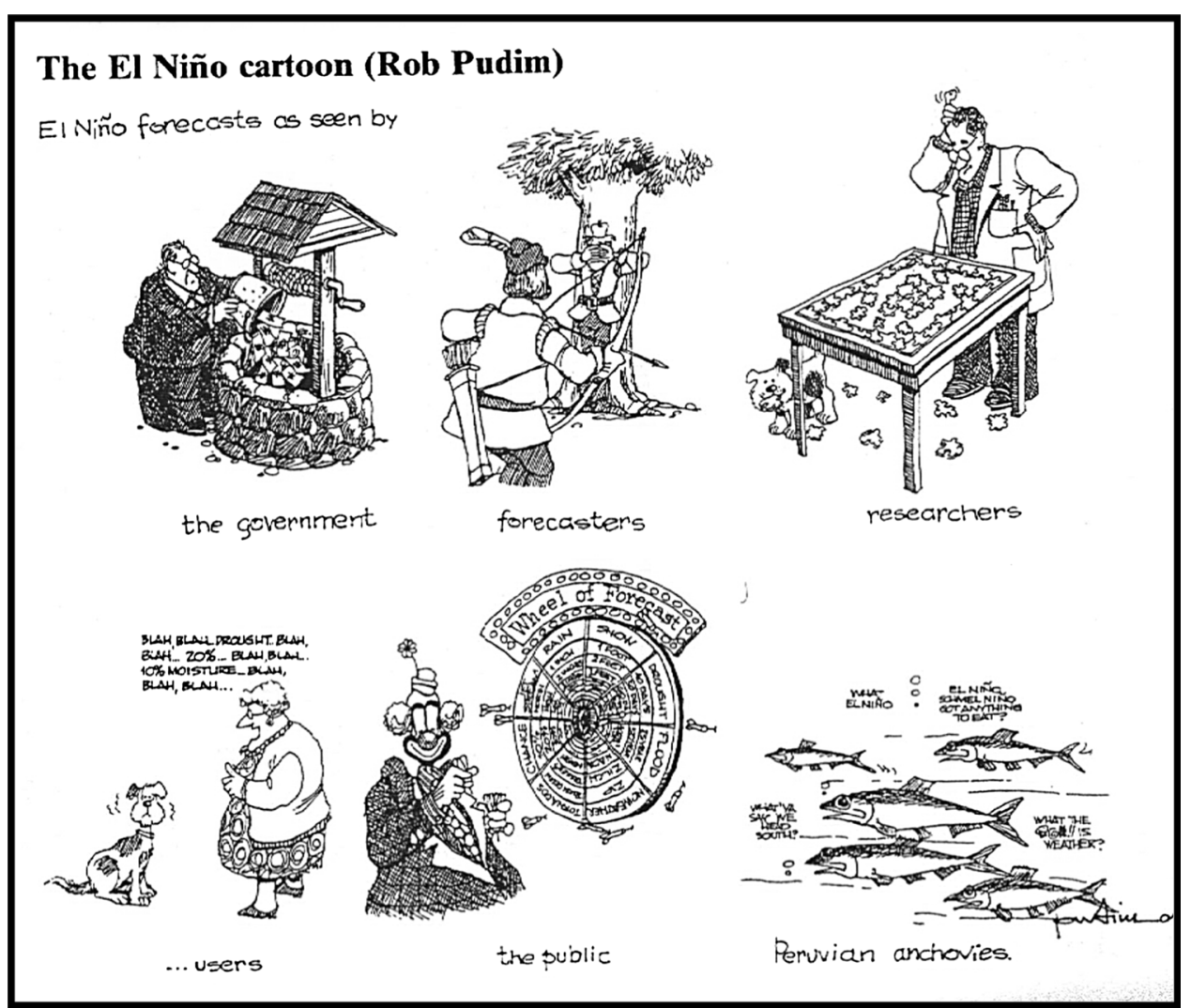

world's oceans that impinge on the behavior and impacts of the ENSO "cycle." But having aroused media interest in the possibility of a major El Niño occurrence, the media followed up when nothing happened. Although some forecasters admitted that the forecast was "a flop," others did not give up on the possibility that an El Niño could occur by the end of 2014. But, if such an event were to occur would it be a different one than the one that had been forecast earlier in the year? This suggests that forecasting El Niño's onset is still experimental and not operational. Forecasting its onset (as a specific event) should be separated from forecasting its behavior (as a process) and impacts once the onset has been assured.

Acknowledgments I would like to acknowledge with many thanks the helpful discussions with and suggestions by Joseph Tribbia (NCAR), Peter Gent (NCAR), Lino Naranjo (MeteoGalicia, Spain), Arielle de la Poterie (University of Colorado), and Robert Ross (CCB, University of Colorado). I am also extremely grateful to the reviewers who put a lot of effort in their review of a draft of this paper. However, the author is responsible for the final tone and content of this paper.

Open Access This article is distributed under the terms of the Creative Commons Attribution License which permits any use, distribution, and reproduction in any medium, provided the original author(s) and the source are credited.

\section{References}

Barnston, A.G., Y. He, and M.H. Glantz. 1999. Predictive skill of statistical and dynamical climate models in SST forecasts during the 1997-98 El Niño episode and the 1998 La Niña onset. Bulletin of the American Meteorological Society 80(2): 217-243.

Barnston, A.G., A. Leetmaa, V.E. Kousky, R.E. Livezey, E. O'Lenic, H. Van den Dool, A.J. Wagner, and D.A. Unger. 1999. NCEP forecasts of the El Niño of 1997-98 and its US impacts. Bulletin of the American Meteorological Society 80(9): 1829-1852.

Bjerknes, J. 1966. A possible response of the atmospheric Hadley circulation to equatorial anomalies of ocean temperature. Tellus 18(4): 820-829.

Bjerknes, J. 1969. Atmospheric teleconnections from the equatorial Pacific. Journal of Physical Oceanography 97(3): 163-172.

FAO (Food and Agriculture Organization). n.d. Total production of Peruvian anchoveta (E. ringens) in the Southeast Pacific (Area 87) and "El Niño" years since 1950. http://www.fao.org/NEWS/ GLOBAL/IMG/anchov-e.gif. Accessed 21 Feb 2015.

Glantz, M.H. 1994. Forecasting El Niño: Science's gift to the 21st century. Ecodecision 12: 78-81.

Glantz, M.H. (ed.). 2001. Once burned twice shy: Lessons learned from the 1997-98 El Niño. Tokyo: United Nations University Press.

Hall, M. 2011. Are you a poet or a mathematician? http://www. agilegeoscience.com/blog/2011/10/13/are-you-a-poet-or-a-math ematician.html?rq=probability. Accessed 22 Feb 2015.

Hendon, H.H., and M.L. Salby. 1994. The life cycle of the MaddenJulian oscillation. Journal of the Atmospheric Sciences 51(15): $2225-2237$. 
International Research Institute, Columbia University and NOAA Climate Prediction Center. 2014. IRI ENSO forecast. 2014 October quick look. http://iri.columbia.edu/our-expertise/cli mate/forecasts/enso/2014-October-quick-look. Accessed $22 \mathrm{Feb}$ 2015.

L'Heureux, M. 2015. Were model predictions of El Niño a Big Bust? http://www.climate.gov/news-features/blogs/enso/were-modelpredictions-el-niño-big-bust. Accessed 22 Feb 2015.

Merriam-Webster. n.d. Merriam-Webster.com. Web. 23 Oct 2014. http://www.merriam-webster.com/dictionary/chaos. Accessed 20 Jan 2015.

Mehta, V. 2004. Decadal climate variability: Societal impacts, phenomena, problems and prospects. Unpublished PowerPoint document. Presented at the SORCE Science Team meeting, Meredith, New Hampshire, 27-29 October. http://lasp.colorado. edu/sorce/news/2004ScienceMeeting/SORCE WORKSHOP 2004/SESSION_3/3_0_Mehta.pdf. Accessed 21 Feb 2015.

Miller, C. 2014. El Niño fizzle: No relief likely for California drought. http://blogs.kqed.org/science/2014/08/07/el-nino-fizzle-no-relieflikely-for-california-drought/. Accessed 21 Feb 2014.
NASA Science News. 2014. El Niño: Is 2014 the new 1997? http:// science.nasa.gov/science-news/science-at-nasa/2014/19may_ elnino/. Accessed 22 Feb 2015.

National Weather Service, U.S.A. n.d. Weather impacts of ENSO. http://oceanservice.noaa.gov/education/yos/resource/JetStream/ tropics/enso_impacts.htm. Accessed $21 \mathrm{Feb} 2015$.

Queensland Government, Australia. n.d. What factors contribute to floods? http://www.chiefscientist.qld.gov.au/publications/under standing-floods/what-factors-contribute. Accessed 21 Feb 2015.

Thompson, A. 2014. Waiting for El Niño. Still. Again. http://www. climatecentral.org/news/still-waiting-for-el-nino-18286. Accessed 22 Feb 2015.

The Hindu. 2014. Strongest in 15 years, 2014 El Niño could hit India hard. 12 Jun 2014. http://www.thehindu.com/sci-tech/energyand-environment/strongest-in-15-years-2014-el-nio-could-hit-indiahard/article6107952.ece. Accessed 20 Jan 2015.

The Watchers. 2014. Super strong El Niño in 2014? http:// thewatchers.adorraeli.com/2014/05/22/super-strong-el-Niño2014/. Accessed 22 Feb 2015. 